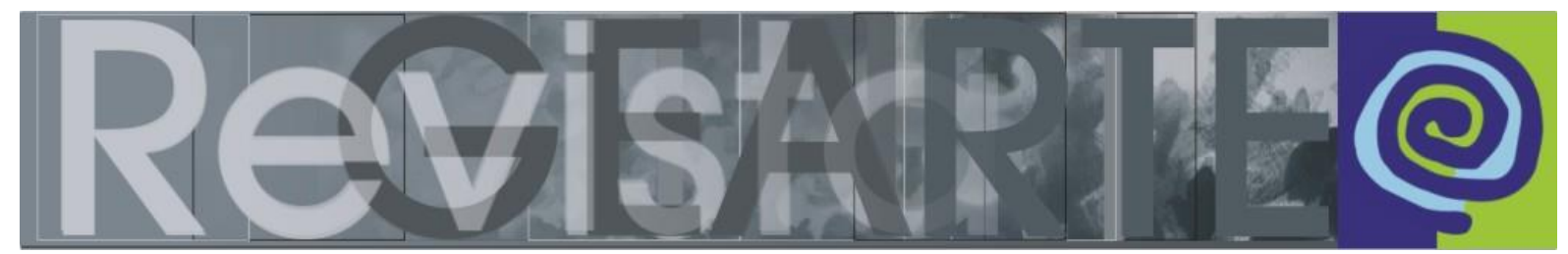

ISSN 2357-9854 | e-ISSN 2596-3198 (online)

\title{
Um fio narrativo de histórias: professoras pioneiras das artes visuais no curso de Pedagogia
}

\author{
Mirian Celeste Martins \\ (Universidade Presbiteriana Mackenzie - MACKENZIE, São Paulo/SP, Brasil) \\ Lucia Maria Salgado dos Santos Lombardi \\ (Universidade Federal de São Carlos - UFSCar, Sorocaba/SP, Brasil)
}

\begin{abstract}
RESUMO - Um fio narrativo de histórias: professoras pioneiras das artes visuais no curso de Pedagogia - $O$ artigo discorre sobre a trajetória educativa de cinco professoras pioneiras no ensino de Artes Visuais no curso de Pedagogia no Brasil: Ana Angélica Albano, Ana Luiza Ruschel Nunes, Analice Dutra Pillar, Maria Felisminda de Rezende e Fusari e Susana Rangel Vieira da Cunha. Narrar sobre a história do surgimento desta área por meio de testemunhos das professoras que abriram caminhos, propicia uma reflexão sobre necessidades, valores, esforços e objetivos mais significativos do campo desde a década de 1980. Entrelaçamos as memórias com as experiências contemporâneas, já que é a partir das nossas heranças que atuamos no constante construir e reconstruir as práticas artísticas e educativas.
\end{abstract}

PALAVRAS-CHAVE

Artes Visuais. Curso de Pedagogia. Biografia de educadores. Ensino de Arte. Formação de professores.

RESUMEN - Un hilo narrativo de historias: profesoras pioneras de las artes visuales en el curso de Pedagogía - El artículo discute la trayectoria educativa de cinco profesoras pioneras en la Educación Artística en el curso de Pedagogía en Brasil: Ana Angélica Albano, Ana Luiza Ruschel Nunes, Analice Dutra Pillar, Maria Felisminda de Rezende e Fusari y Susana Rangel Vieira da Cunha. Narrar sobre la historia del surgimiento de esta área a través de los testimonios de profesoras que abrieron caminos, proporciona una reflexión sobre las necesidades, valores, esfuerzos y objetivos más importantes del campo desde la década de 1980. Entrelazamos recuerdos con experiencias contemporáneas, ya que es a partir de nuestras herencias que actuamos en la constante construcción y reconstrucción de prácticas artísticas y educativas.

PALABRAS CLAVE

Artes Visuales. Curso de Pedagogía. Biografía de los educadores. Educación Artística. Formación de profesores.

\begin{abstract}
A narrative thread of stories: pioneer professors of the visual arts in the Pedagogy course - The article discusses the educational trajectory of five pioneer professors in teaching visual arts in the Pedagogy course in Brazil: Ana Angélica Albano, Ana Luiza Ruschel Nunes, Analice Dutra Pillar, Maria Felisminda de Rezende e Fusari e Susana Rangel Vieira da Cunha. Tell the story of the emergence of this area through the testimonies of the professors who pioneered, provides a reflection on the field's most significant needs, values, efforts and goals since the 1980s. We interweave memories with contemporary experiences, since it is from our inheritance that we act in constant build and reconstruct the artistic and educational practices.
\end{abstract}

KEYWORDS

Visual Arts. Pedagogy course. Educator biography. Art teaching. Teacher training. 


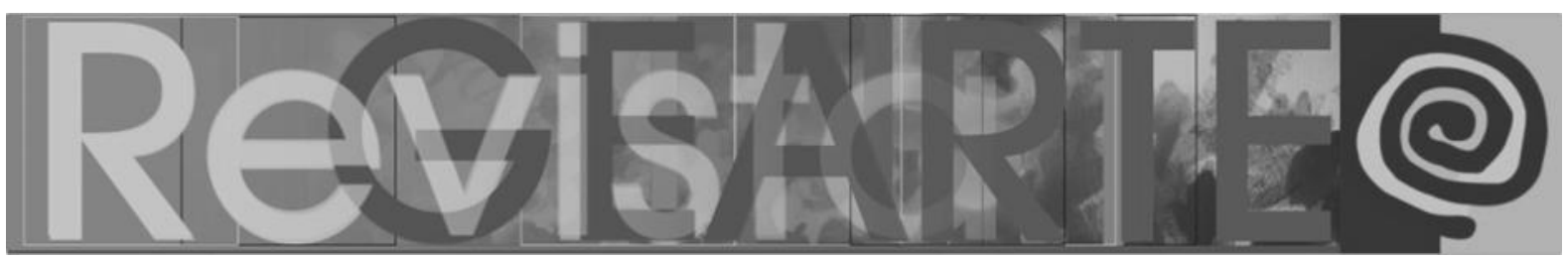

Introdução: "a memória é um cabedal infinito do qual só registramos um fragmento"

"- Eu ainda guardo isso para ter uma memória viva de alguma coisa que possa servir alguém." D. Brites, entrevistada por Ecléa Bosi (1983, p.3)

As histórias de cinco professoras pioneiras no ensino de Artes Visuais no curso de Pedagogia no Brasil, sendo uma in memoriam, Maria Felisminda de Rezende e Fusari - a inesquecível Mariazinha -, Ana Angélica Albano, Ana Luiza Ruschel Nunes, Analice Dutra Pillar e Susana Rangel Vieira da Cunha são objeto deste texto. Como Ecléa Bosi (1983), não pretendemos escrever sobre memória ou abarcar todas as pioneiras das artes visuais que batalharam por mais arte nos cursos de Pedagogia. Apoiamo-nos nas construções biográficas destas professoras como fonte histórica da Arte/Educação e com intencionalidade educativa em função de uma possível exemplaridade nelas contida, tal como revela Carino (2000, p. 163):

\begin{abstract}
Trata-se de explorar a biografia como um instrumento de análise para a prática cultural dos indivíduos, como a expressão corporificada dessa prática. Instrumento tanto mais importante quanto variado, quanto mais "caleidoscópico", ou seja, rico em formas e "cores", correspondentes à variedade de apropriações culturais individuais, às formas originais como as vidas concretas são vividas.
\end{abstract}

Rememorar as experiências das professoras significa explorar uma série de aspectos, dentre os quais, destacamos três eixos articulados entre si: as pesquisadoras e a construção das suas carreiras universitárias, a criação das disciplinas de Arte no curso de Pedagogia e os desafios e transformações do campo.

Puxamos um fio de história visitando as décadas de 1980 e 1990, partindo do início das suas carreiras como professoras e pesquisadoras, mas também, acessando nossas próprias vivências, a fim de revelar as transformações conceituais, metodológicas e legais da área, em seu processo de valorização como área de conhecimento. 


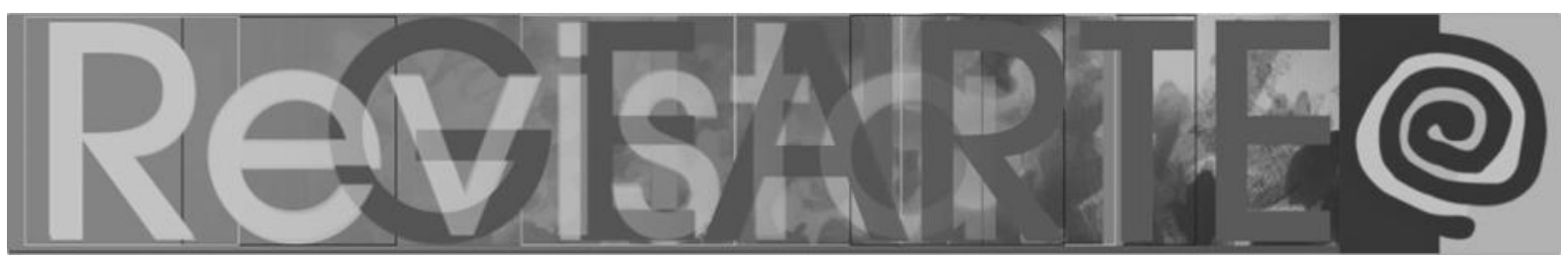

Realizamos uma pesquisa narrativa (MALHEIROS, 2011), utilizando biografias como instrumento de análise (CARINO, 2000). "Lembrança puxa lembrança e seria preciso um escutador infinito", diz Ecléa Bosi (1983, p. 3). Por isso, aqui não se encontram todas as lembranças que afloraram dos testemunhos. Nosso olhar para a memória histórica profissional destas professoras pioneiras é uma abordagem que garante tão somente um convite à reflexão sobre os fundamentos que norteiam nosso campo do saber e de atuação, ao mesmo tempo em que motiva à criação de perspectivas plurais que pulsam hoje nas práticas de docentes de Arte dos cursos de Pedagogia.

\section{Pesquisa narrativa: conhecendo as vivências das professoras pioneiras}

No exercício das construções biográficas das professoras, dialogamos com suas trajetórias, analisando algumas de suas iniciativas a partir de fundamentações teóricas e de nossas vivências na área da formação artística de educadores. Analisamos os discursos coletados seguindo as orientações metodológicas de Malheiros (2011) a respeito da pesquisa narrativa, o qual afirma que narrar é relatar de forma organizada os acontecimentos a fim de compreender as histórias de vida ou histórias sociais de grupos restritos de pessoas. Este pesquisador esclarece que, "como pesquisa qualitativa, esta abordagem não requer um número mínimo de participantes. Pode ser realizada, inclusive, utilizando somente uma pessoa como fonte de dados" (MALHEIROS, 2011, p. 91). Ele elucida que a biografia, quando busca responder a um problema de pesquisa, pode ser considerada uma pesquisa narrativa. Neste caso específico, as respostas aos nossos questionamentos levantaram as experiências profissionais de professoras pioneiras no ensino das Artes Visuais no curso de Pedagogia, contribuindo com a compreensão do nosso campo do saber na contemporaneidade.

Como na pesquisa narrativa não basta coletar informações, mas sim, ser capaz de ler nas entrelinhas dos discursos e analisar as informações 


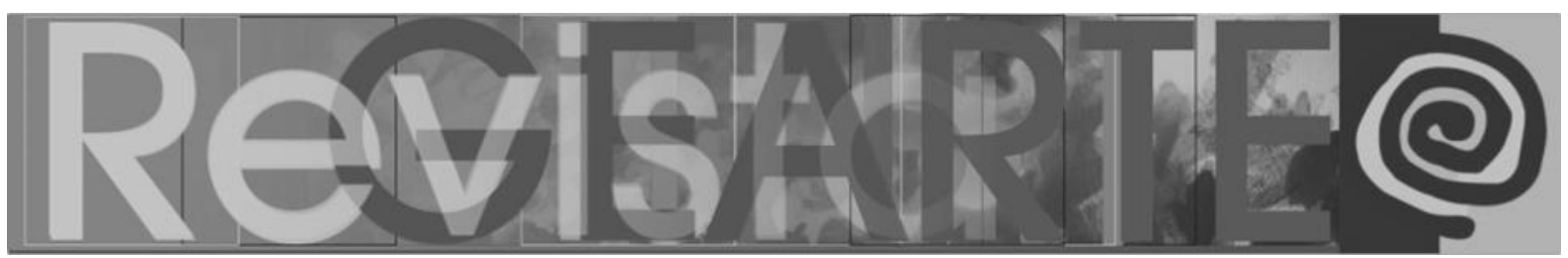

(MALHEIROS, 2011), este artigo se desenvolveu desde a definição do problema o qual nasceu em 2012, em meio ao primeiro levantamento nacional realizado pelo Grupo de Pesquisa Arte na Pedagogia (GPAP) -, a identificação das professoras e a coleta de dados, a qual se deu por meio de entrevistas realizadas por e-mail e por whatsapp, bem como utilizando outras fontes, como livros, artigos e documentos. Por fim, interpretamos e comparamos acontecimentos de forma a olhar para a história não apenas como factual, mas sim, repleta de significados.

Semelhante ao que foi realizado em Lombardi (2011), nesse exercício de memorização e narração nos fazemos tanto ouvintes como narradoras, pois, ao pesquisar memórias de professoras, encontramos um caminho para repensar nossas práticas e conceitos. Como afirma Bosi (1983), a riqueza e a diversidade do mundo social do passado podem chegar até nós através da memória e lapidar a inteligência do presente, misturando-se às percepções do espírito. Enfatiza ela que não existe presente sem passado, já que nossas visões e comportamentos estão marcados pela memória, por eventos e situações vividas. A "alta função da lembrança" é deslocar os feitos do passado para o agora naquilo em que realmente revestiu-se de interesse, significado e importância.

Enfocamos nas experiências que, neste momento, reconhecemos como possuindo relevância para a prática pedagógica em Arte na formação de pedagogos/as. É nessa perspectiva que reiteramos o conceito de Bosi (1983) de que muitas recordações que incorporamos a nossos repertórios não são somente nossas, mas parte de uma substância social com ressonância coletiva que pode imprimir significados não somente em uma pessoa, mas nas subjetividades de outras pessoas. Trata-se, assim, de uma memória coletiva da Arte na Pedagogia, criada em interação e em companhia (LOMBARDI, 2011). 


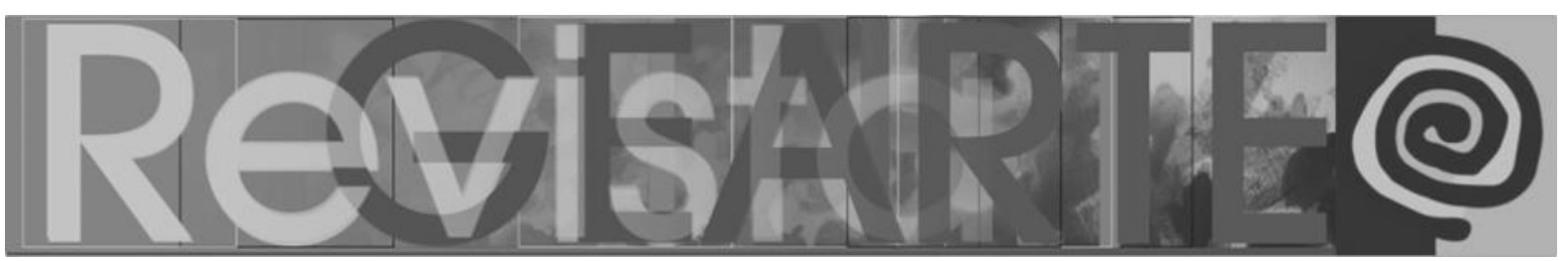

\section{Professoras pesquisadoras que se tornam pioneiras nos cursos de Pedagogia}

Ao olhar para as décadas de 1980 e 1990 e, antes de adentrarmos no curso de Pedagogia, observamos a formação das cinco professoras pioneiras e descobrimos conexões nas suas vidas de pesquisadoras em início de suas carreiras acadêmicas. É por este viés que primeiramente as apresentamos.

Maria Felisminda de Rezende e Fusari (10/11/1940 - 21/04/1999), Mariazinha, como era carinhosamente chamada, em 1956 "iniciou-se na vida profissional como educadora competente e capaz de ensinar o aluno a amar o aprender" (WITTER, 2001, p. 77) como professora da Educação Infantil até os ensinos fundamental e médio. Cursou o mestrado em Psicologia Escolar, no Instituto de Psicologia da Universidade de São Paulo (USP). Sua tese, defendida em 1982, sob a orientação de Geraldina Witter, gerou o livro $O$ educador e o Desenho Animado que a criança vê, o qual apontava para sua preocupação com os profissionais da escola e a necessidade de "desempenharem seu papel diante do aprender a 'ensinar a aprender' a ser um telespectador - adulto e criança verdadeiramente 'comunicador' diante de um processo-projeto-vida, significativo para todas as crianças da realidade brasileira" (FUSARI, 1985, p. 154). Seus estudos continuaram no doutorado no mesmo instituto, defendido em 1989, com o título Meios de Comunicação na Formação do Professor: televisão e vídeo em questão. Por um lado, Mariazinha ampliava a sua contribuição para a educomunicação, viés valorizado por Ana Mae Barbosa (2019), ressaltando que o prêmio anual do Núcleo de Comunicação da Escola de Comunicações e Artes (ECA) da USP, recebe seu nome. Por outro lado, Mariazinha revelava sua sensível atenção para com a formação de professores/as, o que Ihe rendeu também a homenagem de ter seu nome em uma Escola Municipal de Educação Infantil (EMEI), no Jardim Arpoador, São Paulo. Sua generosidade sempre foi admirável, o que levou Ana Mae Barbosa (2019, p. 173) dizer que "ela era ingrediente 'insubstituível' de qualquer exame de qualificação de alunos de Arte/Educação".

MARTINS, Mirian Celeste; LOMBARDI, Lucia Maria Salgado dos Santos. 120

Um fio narrativo de histórias: professoras pioneiras das artes visuais no curso de Pedagogia.

Revista GEARTE, Porto Alegre, v. 7, n. 1, p. 116-132, jan./abr. 2020.

Disponível em: http://seer.ufrgs.br/gearte 


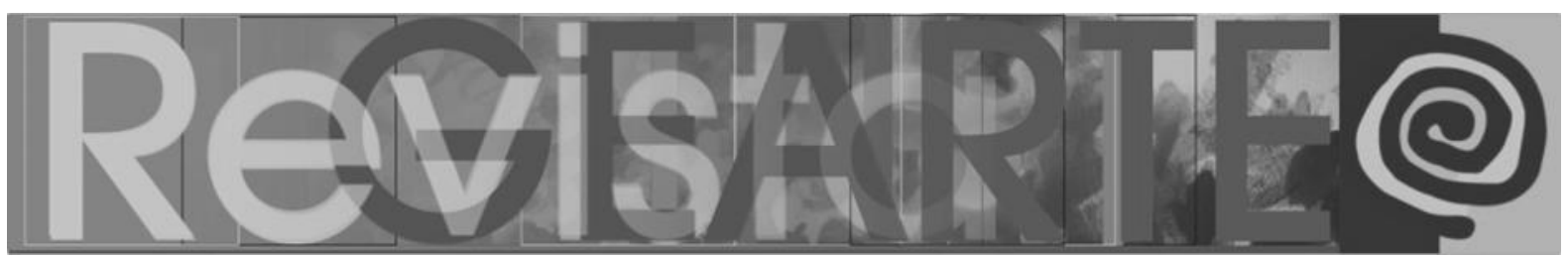

Mirian Celeste é testemunha de sua atenção, por ter sido sua primeira e única doutoranda, já que Mariazinha faleceu pouco antes da defesa.

Ela lecionou em várias escolas até sua importante atuação na Faculdade de Educação da USP e na pós-graduação na ECA em cursos lato senso (1989) e posteriormente em stricto senso (1990). Lá, com sua parceira Maria Heloísa Corrêa de Toledo Ferraz, produziu livros que são até os dias de hoje fundamentação teórica essencial: Arte na educação escolar - publicado em 1992, teve sua $4^{a}$. edição em 2010 -, e Metodologia do ensino da arte: fundamentos e proposições - publicado em 1993, teve sua $3^{a}$. edição, revisada e ampliada por Heloíza Ferraz, publicada em 2018.

Ana Angélica Moreira Albano, conhecida como Nana, cursou o mestrado no Instituto de Psicologia da USP, com orientação de Lino de Macedo, na mesma época que Mariazinha. Defendida em 1983, sua dissertação foi publicada com o mesmo título, O Espaço do Desenho: a educação do educador, o qual teve em 2013 sua décima sexta edição. No mesmo Instituto, defendeu o doutorado na Psicologia Social em 1995, com título Tuneu, Tarsila e Outros Mestres: uma história de iniciação, tendo como orientador João Augusto Frayze Pereira. Sua caminhada está registrada em um livro publicado em 2018, chamado Conversas com jovens professores de arte, o qual revela sua jornada desde o grande quintal na sua casa de infância, até a formação inicial, a gestão cultural e a formação de professores/as. A leitura nos convida a conhecer a história de sua atuação na Faculdade de Educação da Universidade Estadual de Campinas (UNICAMP) desde 1997, quando assumiu a disciplina de Didática do Ensino de Educação Artística e outra no curso de Especialização em Ciência, Arte e Prática Pedagógica, coordenado por Maria José Pereira de Almeida e Célia Maria de Castro Almeida. Em 2016 celebrou a livre-docência na UNICAMP, com título "Memórias", que se transformou no livro publicado em 2018.

MARTINS, Mirian Celeste; LOMBARDI, Lucia Maria Salgado dos Santos. 


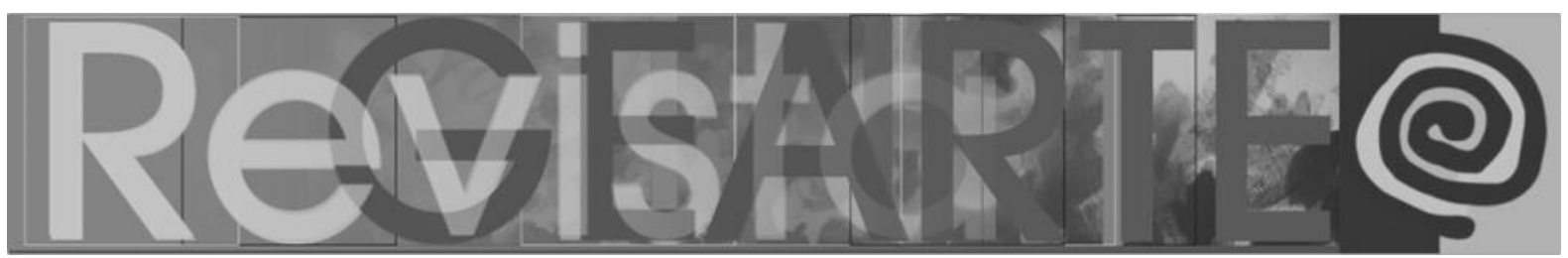

Mariazinha e Nana se conheceram no Grupo Escolar Experimental da Lapa em 1968, uma escola onde a inovação e a interdisciplinaridade eram marcas conceituais que operavam as práticas. Mariazinha, chegada da França, era responsável pelo departamento de audiovisual e Nana fez estágio com ela. Depois foram colegas em muitos cursos e contemporâneas na USP.

Analice Dutra Pillar, foi contemporânea delas duas na USP, onde cursou o mestrado na ECA, com orientação de Ana Mae Barbosa. Com o título Desenho e escrita como sistemas de representação, a dissertação defendida em 1990 se tornou livro em 1996 e que teve uma nova edição revista e ampliada em 2012. Em 1994 terminou o doutorado na mesma instituição e com a mesma orientadora com o título: Desenho e construção de conhecimento na criança, também publicado em 1996. Suas pesquisas a levaram a ingressar na Universidade Federal do Rio Grande do Sul (UFRGS), em 1993. Entre 2012 e 2013 realizou o Pós-Doutorado na Universidade Complutense de Madri, Espanha, com Maria Acaso. Continua a publicar livros, artigos e a coordenar o Grupo de Pesquisa em Educação e Arte (GEARTE), que tem revista de mesmo nome, com chancela da UFRGS, onde continua atuando.

Ana Luiza Ruschel Nunes cursou Licenciatura curta em Educação Artística e Licenciatura plena em Artes Plásticas, ambas na Universidade Federal de Santa Maria (UFSM). Defendeu sua pesquisa de mestrado com o título Pressupostos teóricos para o Ensino das Artes Plásticas na Escola Brasileira em 1990, na mesma universidade. Antes disso, em 1984, estando no cargo de professora da Secretaria de Estado da Educação, foi cedida para ministrar aulas no curso de Pedagogia e no de Artes Plásticas e Desenho da UFSM, no Departamento de Metodologia de Ensino. Seu doutorado foi defendido na UNICAMP em 1997, com o título: Revendo os vínculos entre Trabalho - Arte e Educação. Entre 2016 e 2017 realizou o Pósdoutorado na Universidade do Estado de Santa Catarina (UDESC). Desde 2007 é docente na Universidade Estadual de Ponta Grossa (UEPG), Paraná, continuando a publicar livros e artigos que fortalecem a nossa área. 


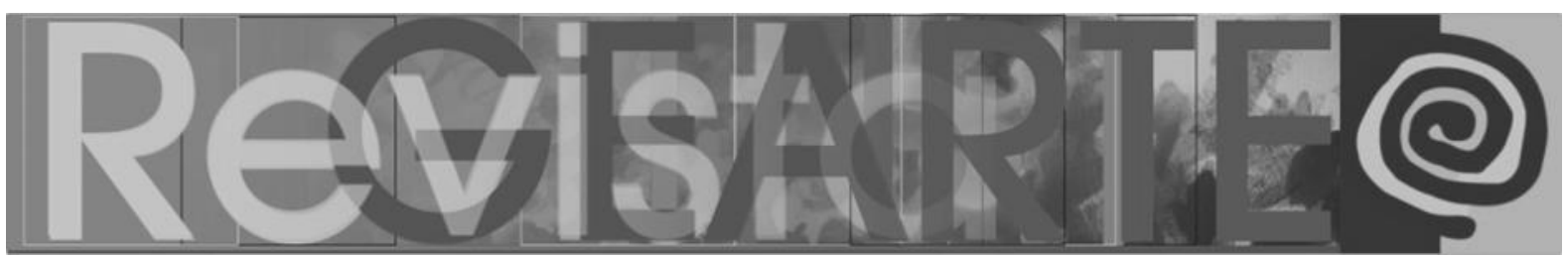

Susana Rangel Vieira da Cunha se formou em Licenciatura em Artes Plásticas em 1983 e defendeu o mestrado em 1992 na Universidade Federal do Rio Grande do Sul (UFRGS), com o título: Educação Artística e conhecimento da realidade. Em 1997, ingressou nesta universidade em concurso para a implementação de uma disciplina de Arte para a Educação Infantil. Em 2005, defendeu sua tese de doutorado na mesma universidade, tendo por título Educação e Cultura Visual: uma trama entre imagens e infância, com orientação de Analice Dutra Pillar e co-orientação de Fernando Hernández, da Universidade de Barcelona, Espanha. Entre 2014 e 2015 realizou seu Pós-Doutorado no Instituto de Educação e Psicologia da Universidade do Minho, Portugal, e na Universidade Barcelona. Hoje, aposentada, continua atuante em variados cursos e consultorias em Arte e Educação Infantil e realizando pesquisas que levam à publicação de artigos e livros resistentes e vigorosos sobre o ensino de Arte na Educação Infantil, a investigação de materiais, as relações entre arte contemporânea e as múltiplas infâncias.

As cinco professoras, todas com graduação em Arte e atentas às suas próprias formações, marcaram o ensino de Artes Visuais nos cursos de Pedagogia, atuando no desenvolvimento profissional de pedagogo/as no sentido de considerar as relações intrínsecas entre graduação, pós-graduação e formação continuada, entre ensino e pesquisa, entre as teorias, práticas e políticas que permeiam os temas com os quais trabalhamos, tais como o dos estudos da cultura visual, dos conceitos de infâncias, crianças, arte contemporânea e mediação cultural.

\section{A criação das disciplinas de Arte nos cursos de Pedagogia, os desafios e as transformações do campo}

Atualmente, é dada ênfase ao ensino de Arte como área de conhecimento em todos os níveis escolares e universitários, dentre os quais, na formação inicial de pedagogos/as. As cinco professoras cujas trajetórias são tomadas aqui como fonte histórica, se formaram e iniciaram suas carreiras universitárias em um 


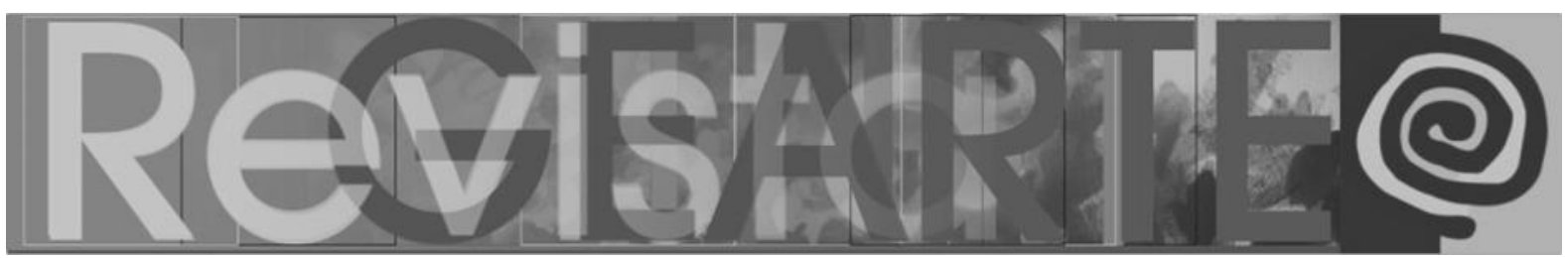

momento do ensino de Arte ainda conhecido como "Educação Artística", regido pela segunda Lei de Diretrizes e Bases da Educação (LDB) no Brasil, a № 5.692, de 11/08/1971, passando depois por processos de legitimação do campo que levaram a transformações sócio-políticas, histórico-culturais e legais.

Recorrendo aos percursos das cinco pioneiras, podemos perceber mais sobre como essas transformações na área aconteceram, desde a década de 1980. Metamorfoses que se fizeram indispensáveis mediante o compromisso assumido de saber arte e saber ser professora de Arte, com atitude de constante meditação sobre as necessidades, os valores e os objetivos mais significativos do campo, entrelaçados com as experiências contemporâneas e as infâncias do presente. Observamos que os ganhos para a área vieram da atitude das professoras de assumirem a luta de mobilizar a categoria docente, as crianças, as juventudes e as comunidades para a necessidade da arte. A atuação política de Mariazinha é exemplo disso, representando uma ação contundente em relação à defesa do ensino de Arte no curso de Pedagogia. Ela foi porta-voz da necessidade da implantação de uma disciplina de Fundamentos da Arte/Educação neste curso em variados momentos de luta que resultaram na escritura de documentos tais como: as conclusões do I Congresso Nacional de Arte e Educação/Salvador em 1983; no Manifesto de Diamantina, em 1985; na Carta de São João Del-Rei, em 1986; no Manifesto dos Arte-Educadores do Estado de São Paulo, em 1987 (MARTINS e LOMBARDI, 2015; FARIA et al, 2019).

Como afirma Bosi (1983, p. 29), "a narração da própria vida é o testemunho mais eloquente dos modos que a pessoa tem de lembrar." Então, perguntamos às professoras como tudo começou. Elas aceitaram o convite para o diálogo, se declarando "emocionadas" por rememorar junto conosco: nas palavras de Ana Luiza, "vivendo em tempo de muitas reflexões e sensibilidade, com lembranças e 


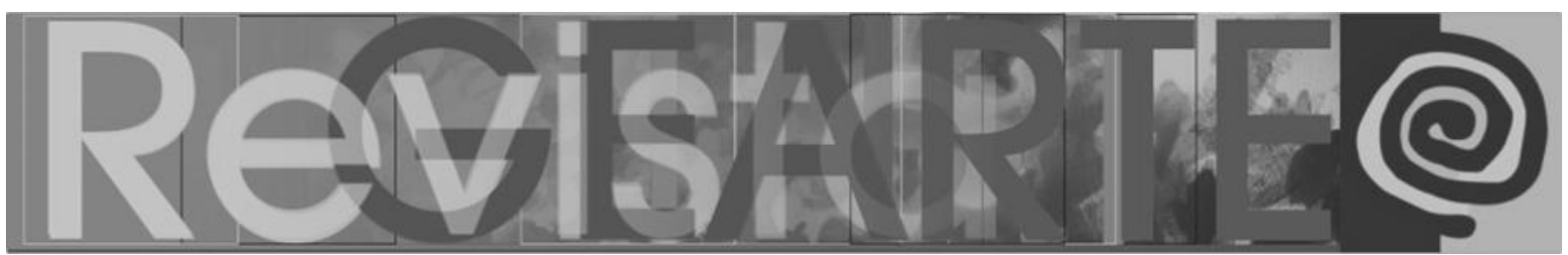

memória em ação". ${ }^{1}$ A "memória em ação" de Ana Luiza, é tida por Bosi (1983, p.

17) em seu caráter de reconstrução, quando a autora afirma:

Na maior parte das vezes, lembrar não é reviver, mas refazer, reconstruir, repensar, com imagens e ideias de hoje, as experiências do passado. A memória não é sonho, é trabalho. [...] A lembrança é uma imagem construída pelos materiais que estão, agora, à nossa disposição, no conjunto de representações que povoam nossa consciência atual.

Ana Luiza Ruschel Nunes iniciou em 1984 sua atuação com Arte nos cursos de Pedagogia, de Educação Artística, de Artes Plásticas e de Desenho, todos estes licenciaturas. Ela relata que quem idealizou a inserção da Arte na Pedagogia foram a Prof ${ }^{-}$Dr ${ }^{a}$ Santa Marli Pires dos Santos e a Prof ${ }^{-}$Dr ${ }^{a}$ Nilce Helena Pippi Carvalho. ${ }^{2}$ Informa que havia dois cursos, "Pedagogia em Educação Infantil" e "Pedagogia nos Anos Iniciais" nos quais foram implantadas a disciplina de "Metodologia do Ensino de Artes Plásticas na Educação Infantil" e "Metodologia do Ensino de Artes Plásticas para as séries iniciais". Ela atuou em ambas desde sua implementação e conta ${ }^{3}$ que:

Pela falta de professores na UFSM havia um sistema de cedência da Secretaria de Educação do Estado do Rio Grande do Sul para a Universidade Federal de Santa Maria, através de convênio. Neste contexto, fui convidada por ofício do Reitor e do Diretor do Centro de Educação da UFSM para ministrar disciplinas de Arte no curso de Pedagogia em Educação Infantil, de Pedagogia nos Anos Iniciais, de Educação Artística (Licenciatura curta), de Licenciatura em Desenho e Plástica. Em 1988 fiz concurso e só chamaram em agosto de 1989, no Centro de Educação, onde ingressei como efetiva.

Sobre a realização do trabalho desde aqueles princípios, Ana Luiza afirma:

O trabalho realizado era muito qualificado para aquele contexto! Uma práxis de experiências e vivências estéticas com poéticas de criação artística, com exposição da produção, criação do Laboratório de Artes Visuais e criação de jogos de arte que envolviam o desenvolvimento

1 Informação de Ana Luiza Ruschel Nunes enviada por e-mail em agosto/2019.

2 Oesterreich (2010) afirma que a professora Nilce Helena Pippi Carvalho foi a primeira docente responsável pela disciplina de Música na Pedagogia, seguida pela Prof ${ }^{a}$. Dr ${ }^{\mathrm{a}}$. Cláudia Ribeiro Bellochio, atual professora efetiva que trabalha com a disciplina de Música no curso.

3 Informação de Ana Luiza Ruschel Nunes enviada por whatsapp em agosto/2019. 


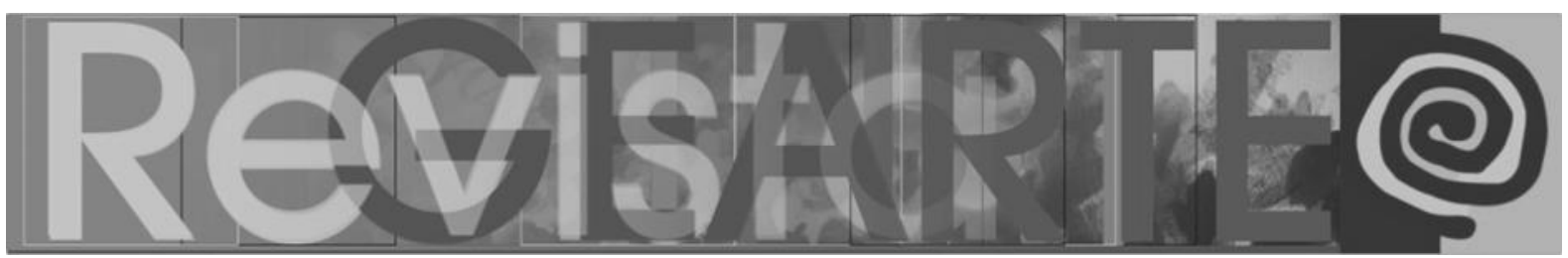

cognitivo com cor, textura, forma, além de experiências pictóricas, gravura, criação têxtil, expressão com três dimensões com argila e madeira. Estudos do desenvolvimento infantil e da adolescência, com interpretação do desenho e pintura no desenvolvimento e aprendizagem da arte gráfica, inter-relacionada com a escrita e processo de alfabetização ${ }^{4}$.

Mariazinha começou a atuar com Arte no curso de Pedagogia da Faculdade de Educação da USP em 1988 como professora da disciplina eletiva "Arte na educação escolar", com duas turmas (diurno e noturno) de até 60 estudantes em cada, tendo quatro horas semanais (FUSARI, 1999, p. 6). Sobre este trabalho, Mariazinha relata em seu memorial que, de $1990 \mathrm{em}$ diante...

[...] além de estudantes de Pedagogia, têm participado das aulas dessas disciplinas, alguns professores (dez em cada turma) em exercício nas Pré-Escolas e Escolas de $1^{\circ}$ e $2^{\circ}$ Graus Municipais e Estaduais (Subprojeto de Cursos de Extensão FEUSP "Professores da Rede Pública Como Alunos Especiais") e pessoas da "terceira idade". (FUSARI, 1999$, p. 6$)^{5}$.

Deste modo, havia a possibilidade de ampliação da compreensão da importância da arte não somente na formação inicial de educadores, mas também na continuada, batalha esta que move também o Grupo de Pesquisa Arte na Pedagogia (GPAP) desde a sua formação.

Por outro lado, na Universidade Federal do Rio Grande do Sul, na Licenciatura em Artes, nos conta Susana que já existia uma disciplina de Arte na Pedagogia, cuja professora era Denyse Vieira. No curso específico de Pedagogia, em 1991, o cenário da área de Arte estava restrito a uma disciplina no currículo do curso de Pedagogia: "Educação e Arte: expressão plástica, dramática e musical", com caráter obrigatório, envolvendo as linguagens das artes plásticas, do teatro e da música.

4 Informação de Ana Luiza Ruschel Nunes enviada por whatsapp em setembro/2019.

5 O Memorial/Curriculum Vitae de Mariazinha nos foi gentilmente cedido pelo Prof. Dr. José Cerchi Fusari, seu marido. 


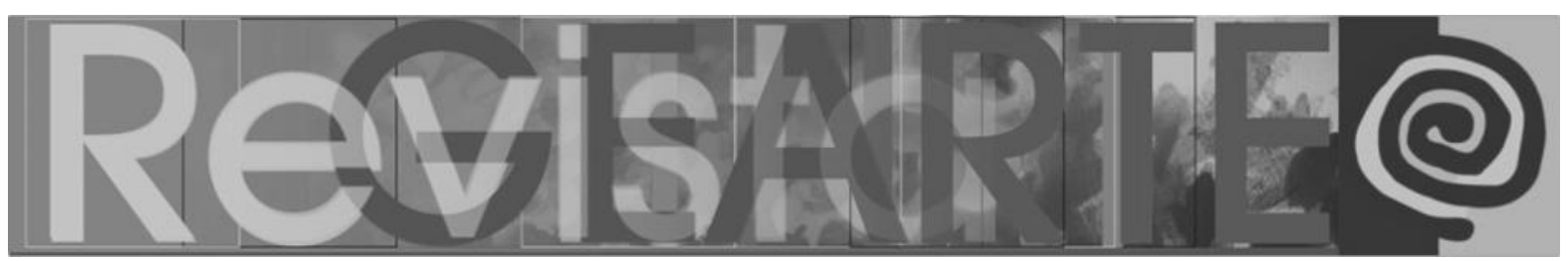

Analice, com formação em Artes Visuais, nos revela em seu depoimento por e-mail, em agosto de 2019:

\begin{abstract}
Eu ministrava aulas nesta área e convidava professores de teatro e de música para ministrarem umas ou duas aulas, cada um, ao grupo. Meu desejo era ampliar a área de artes dentro do currículo do curso com disciplinas nas demais linguagens e com professores das áreas. Ao longo dos anos fomos conseguindo essas conquistas e a última foi incluir as quatro áreas de artes no currículo com uma disciplina de dança, que está como alternativa por não termos professor concursado ainda. Depois, em 1994, com a transferência de um professor de teatro para a Faculdade de Educação, a disciplina foi desmembrada em duas e passou a chamar-se "Educação e Arte: expressão plástica" e "Educação e Arte: expressão dramática e musical", ambas obrigatórias e com 3 créditos. Nessa mesma época, com o ingresso de outra professora de artes visuais e uma de música, foram criadas duas disciplinas específicas para educação infantil: "Arte na Educação Infantil" e "Música na Educação Infantil".
\end{abstract}

Susana Rangel Vieira da Cunha iniciou a docência em Arte no curso de Pedagogia em fevereiro de 1997, ingressando pelo concurso para a implementação de uma disciplina denominada "Arte na Educação Infantil", pois não existiam então disciplinas para formação específica de pedagogas/os que trabalhariam com crianças de 4 meses aos 6 anos de idade. Susana conta que também ministrou a disciplina de Analice como professora substituta em sua licença para a realização do Pós-Doutorado. ${ }^{6}$ Com uma nova reestruturação, devido à determinação do Ministério da Educação, o curso de Pedagogia deixou de ter duas habilitações específicas (para os Anos Iniciais e para Educação Infantil) e passou a ter ênfase única com habilitação para Anos Iniciais, Educação Infantil, Educação de Jovens e Adultos, Educação Especial e Gestão. Com esta configuração, o currículo passou a ter três disciplinas de Arte, de caráter obrigatório, com professores especializados em cada área: "Educação e Artes Visuais", "Educação e Teatro" e "Educação Musical". Desde 2018 além das obrigatórias, foi incluída "Educação e Dança", alternativa, com 3 créditos. ${ }^{7}$

6 Informação de Susana Rangel Vieira da Cunha enviada por e-mail em agosto/2019.

7 Informação de Analice Dutra Pillar enviada por e-mail em agosto/2019

MARTINS, Mirian Celeste; LOMBARDI, Lucia Maria Salgado dos Santos. 


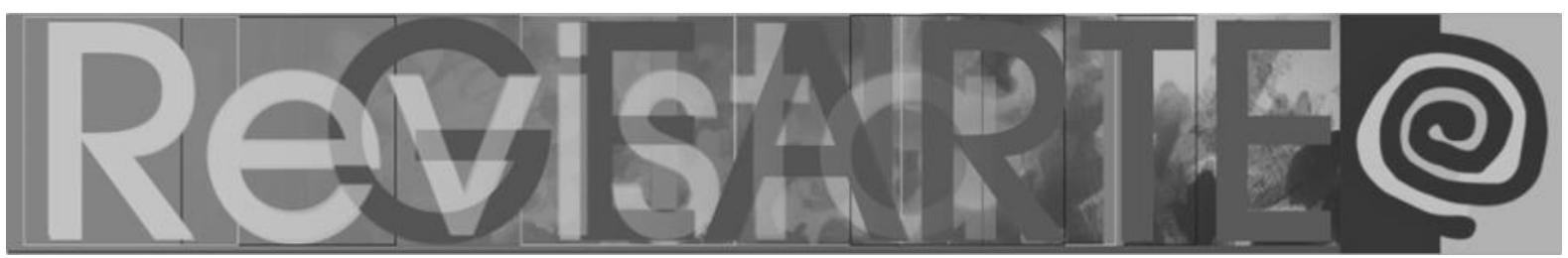

Ana Angélica Albano, aposentada pela UNICAMP, trouxe sua experiência "como professora de artes visuais de crianças e adolescentes em escolas de ensino formal e não formal; como gestora, coordenadora e formadora de professores e artistas em espaços culturais" (ALBANO, 2018, p. 106) para o curso de Pedagogia em 1999. Nana propõe a visibilidade de um trabalho interdisciplinar realizado dentro da sala de aula de Arte, pois junto às professoras Carmen Lúcia Soares e Eliana Ayoub, criou a disciplina "Educação, Corpo e Arte" no curso de Pedagogia, "que, posteriormente, foi compartilhada também com a professora Márcia Strazzacappa e com o professor Adilson Nascimento de Jesus." (ALBANO, 2018, p. 126). Ana Angélica (2018) afirma que a criação desta disciplina no curso de Pedagogia foi extremamente significante para ela, apresentando-se como um desafio interessante por integrar diferentes docentes e solicitar um trabalho em equipe.

"O passado entra plasticamente no universo pessoal" (BOSI, 1983, p. 28). As memórias das professoras conservam o passado, mas são também formas repletas de maleabilidade e recriação. Junto a estas cinco pioneiras da Arte na Pedagogia assumimos esta dimensão como intencional, proposital, provocadora de reconstruções e essencial, reafirmando o desejo de ressemantizar o ensino de Arte, interessadas em pensar sobre as perspectivas para seu ensino no século $\mathrm{XXI}$, dispensando "receitas de métodos e respostas prontas ou pré-fabricadas, buscando diálogos inventivos no coletivo que possam levar a um constante redespertar para modos conscientes de educar em tempos atuais" (MARTINS e LOMBARDI, 2018).

Se é a partir das nossas heranças que atuamos no constante construir e reconstruir das práticas artísticas e educativas, perguntar às pioneiras sobre os primórdios significa repetir a questão já feita por Ana Mae Barbosa (2012): como a Arte/Educação mudou? Que mudanças são essas? 


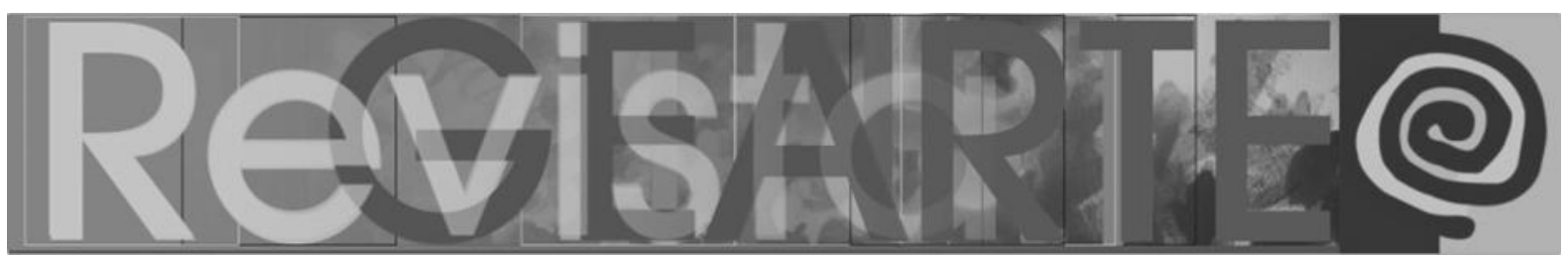

Analice relata que a Arte que realizava na Pedagogia estava, nos primeiros anos, muito centrada nos processos gráfico-plásticos da criança, mesclando ações no atelier de linguagens das artes visuais com propostas para diferentes idades e contextos. Depois o foco foi mudando, mas sempre mantendo a articulação dos trabalhos de atelier nas linguagens artísticas com reflexões teóricas, entrelaçando com estudos da área. Ela afirma:

Os estudos sobre o desenho infantil foram ampliados e atualizados. E outros temas tomaram mais espaço: as tendências contemporâneas do ensino da arte; as relações entre a modernidade na arte e no ensino da arte; a arte contemporânea e o ensino da arte; as relações entre cinema, vídeo e educação. O que posso perceber é que as artes, hoje, fazem partes dos planejamentos dos pedagogos e das pedagogas nos diferentes contextos em que atuam tanto em suas práticas docentes como em seus estágios. Essa constatação é ressaltada pelos demais colegas que atuam no curso de Pedagogia ${ }^{8}$.

$\mathrm{Na}$ companhia dos fios narrativos destas professoras pioneiras e de Ana Mae Barbosa, observamos que a caminhada possibilitou transformações. Barbosa (2012) afirma que até os anos 1980 o compromisso da Arte era apenas com o desenvolvimento da expressão pessoal do/da estudante. Hoje, ao potencial expressivo acrescenta-se maior compromisso com as culturas e a livreinterpretação das obras de arte, com base na ideia de que todos/as podemos compreender e usufruir da arte.

Ainda segundo Ana Mae, a ênfase está na interrelação entre o fazer, a apreciação interpretativa e a contextualização histórica, social, antropológica e/ou estética da obra: "Não se trata mais de perguntar o que o artista quis dizer em uma obra, mas o que a obra nos diz, aqui e agora em nosso contexto e o que disse em outros contextos históricos a outros leitores" (BARBOSA, 2012, p. 19-20).

Não mais se pretende desenvolver apenas uma vaga sensibilidade nos alunos por meio da Arte, mas também se aspira influir positivamente no desenvolvimento cultural dos estudantes pelo ensino/aprendizagem da

8 Informação de Analice Dutra Pillar enviada por e-mail em agosto/2019

MARTINS, Mirian Celeste; LOMBARDI, Lucia Maria Salgado dos Santos. 129

Um fio narrativo de histórias: professoras pioneiras das artes visuais no curso de Pedagogia.

Revista GEARTE, Porto Alegre, v. 7, n. 1, p. 116-132, jan./abr. 2020.

Disponível em: http://seer.ufrgs.br/gearte 


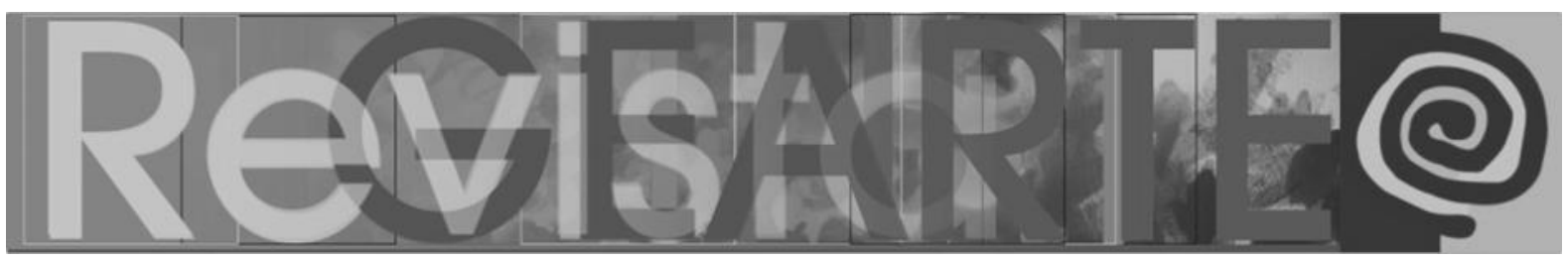

Arte. Não podemos entender a Cultura de um país sem conhecer sua arte. (BARBOSA, 2012, p. 18)

Estas professoras pioneiras atravessaram espaços e tempos sendo sujeitos de mudanças nas tendências pedagógicas, conteúdos e métodos. Hoje seguimos juntas, nos esforçando para fazer uma educação decolonial, compromissada com a diversidade cultural e contextualizada nas comunidades, em defesa dos direitos das crianças e vendo o mundo desde seu ponto de vista poético e explorador.

No que diz respeito a esta singela homenagem às pioneiras da Arte na Pedagogia, desejamos recordar as palavras de Heloísa e Mariazinha: "nosso objetivo principal é situarmo-nos no processo histórico para uma compreensão e posicionamento sobre o ensino e aprendizagem de arte na atualidade. Entretanto, permanece ainda a questão: como pretendemos dar continuidade à essa história?" (FERRAZ e FUSARI, 2010, p. 46).

\section{Considerações para seguir adiante}

Discorremos sobre as trajetórias de mulheres professoras de corpo inteiro, artistas, pesquisadoras, militantes da Arte/Educação, de uma educação libertadora. Como um caleidoscópio rico em formas e cores, elas nos trazem referências essenciais para a construção do campo da Arte dentro do curso de Pedagogia, por terem atribuído ao ensino de Arte neste contexto a função de tempo-lugar de acesso às culturas e à linguagem visual, pretendendo a formação integral da pessoa, de forma que futuros/as pedagogos/as possam ser cidadãos plenos e mediadores culturais mais conscientes. Considerando a escola, pedagogos/as são os/as primeiros/as mediadores/as daquilo que as crianças assistem, escutam e criam. $\mathrm{O}$ ensino de Arte se insere neste contexto contribuindo com o reavivamento do olhar e a atitude crítica, para que sejam capazes de realizar curadorias educativas mais ricas.

Os relatos das professoras demonstram que, para além de compor o quadro da formação acadêmica de pedagogos/as com mais uma disciplina de 


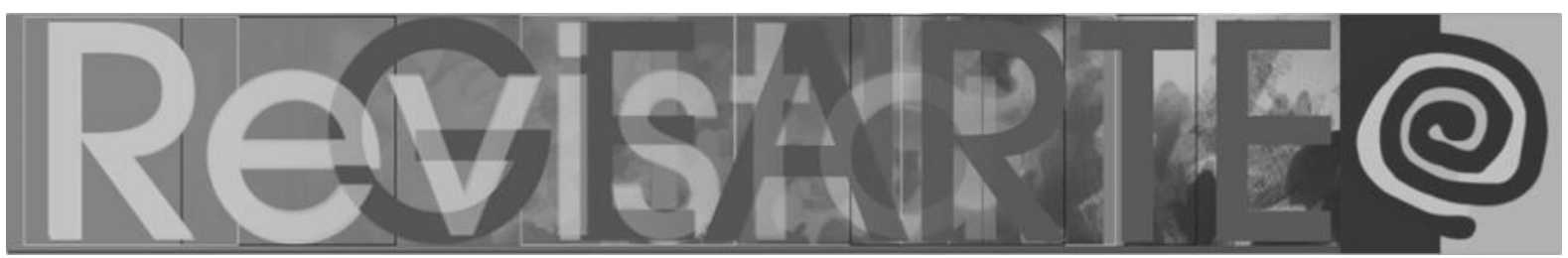

"Metodologia do Ensino", o fazer-fruir-contextualizar das artes neste curso constrói um modo artístico, estético e crítico de educadores/as se relacionarem com o mundo, com a educação e as crianças. Estas professoras pioneiras, por meio de suas biografias, nos deixam um legado de luta e esperança dentro do campo do ensino de Artes Visuais nos cursos de Pedagogia brasileiros. E nos convidam a pesquisar as pioneiras e os pioneiros da Música, do Teatro e da Dança. Gente de luta, que continua a nos impulsionar pela força de suas ações.

\section{Referências}

ALBANO, Ana Angélica. Conversas com jovens professores de arte. São Paulo: Edições Loyola, 2018.

BARBOSA, Ana Mae. As mutações do conceito e da prática. In: Barbosa, Ana Mae (org.) Inquietações e mudanças no ensino de arte. 7ª̣. ed. São Paulo: Cortez, 2012, p. 13-27.

BARBOSA, Ana Mae. O século XXI sem Mariazinha. In: BARBOSA, Ana Mae e AMARAL, Vitória (orgs.). Mulheres não devem ficar em silêncio: arte design, educação. São Paulo, Cortez, 2019, p. 171-175.

BOSI, Ecléa. Memória e sociedade: lembranças de velhos. São Paulo: Cia das Letras, 1983.

CARINO, Jonaedson. A biografia como fonte para a história da educação: subsídios para um debate necessário. Educação \& Filosofia v. 14, n. 27/28, p. 159-173, jan./dez. 2000.

FERRAZ, Maria Heloísa Corrêa de Toledo; FUSARI, Maria Felisminda de Rezende e. Arte na educação escolar. 4⿳亠丷. . ed. São Paulo: Cortez, 2010.

FERRAZ, Maria Heloísa Corrêa de Toledo; FUSARI, Maria Felisminda de Rezende e. Metodologia do Ensino de Arte: fundamentos e proposições. 3a. ed. rev. e ampl. São Paulo: Cortez, 2018.

FARIA, Alessandra Ancona de; BONCI, Estela; WOSNIAK, Fabio; LOMBARDI, Lucia; AMERICANO, Renata; MARTINS, Mirian. Arte na Pedagogia: um coletivo em pesquisa. In: MARTINS, Mirian Celeste; FARIA, Alessandra Ancona de; LOMBARDI, Lucia M. S. S. (orgs.). Formação de educadores: contaminações interdisciplinares com Arte na Pedagogia e na mediação cultural. São Paulo: Terracota, 2019, p.148-167.

FUSARI, Maria Felisminda de Rezende e. Memorial/Curriculum Vitae. Faculdade de Educação, Universidade de São Paulo: São Paulo, 1999.

LOMBARDI, Lucia M.S.S. Formação corporal de professoras de bebês: contribuições da Pedagogia do Teatro. 2011. Tese (Doutorado em Educação). Faculdade de Educação, Universidade de São Paulo, São Paulo, 2011.

MALHEIROS, Bruno Taranto. Metodologia de Pesquisa em Educação. Rio de Janeiro: LTC, 2011. MARTINS, Mirian Celeste; LOMBARDI, Lucia Maria Salgado dos Santos. Arte contemporânea no curso de Pedagogia. In: GUIMARÃES, L.; REGO, L. (Orgs.). Ações políticas de/para enfrentamentos, resistências e recriações: Anais do XXVIII Congresso Nacional da Federação de Arte/Educadores do Brasil e VI Congresso Internacional dos Arte/Educadores. Brasília, DF, 2018. 


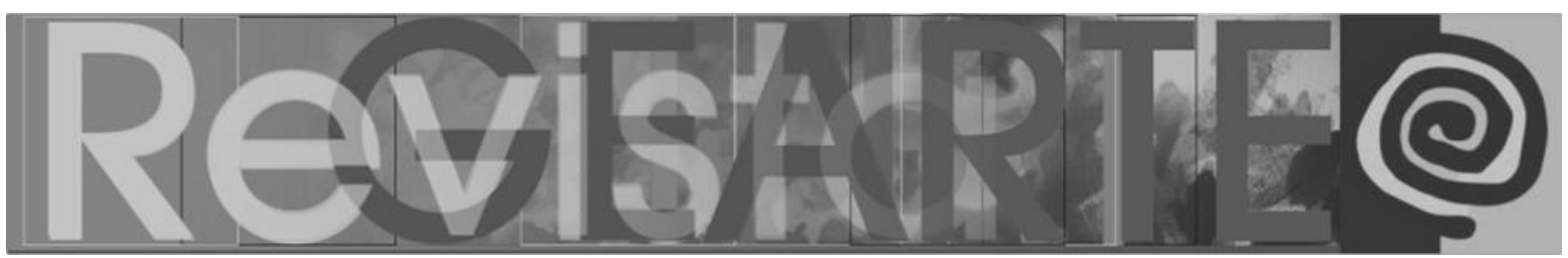

MARTINS, Mirian Celeste; LOMBARDI, Lucia Maria Salgado dos Santos. A Arte na Pedagogia e a formação do professor para Educação Infantil e Anos Iniciais: inquietações e esperanças. Revista Trama Interdisciplinar, São Paulo, v. 6, n. 2, Dossiê Arte na Pedagogia, p. 23-36, maio/ago. 2015.

OESTERREICH, Frankiele. A história da disciplina de Música no curso de Pedagogia da UFSM (1984-2008). Dissertação (Mestrado em Educação). Universidade Federal de Santa Maria (UFSM, RS), 2010.

WITTER, Geraldina Porto. Homenagem a Maria Felismina de Rezende e Fuzari. Psicologia Escolar e Educacional. Campinas, v.5, n.2, p.77-78, Dec. 2001. Disponível em: <http://www.s cielo.br/scielo.php?script=sci_arttext\&pid=S1413-85572001000200011\&lng=en\&nrm=iso $>$.

Acesso em 08 set. 2019.

\section{Mirian Celeste Martins}

Professora do Curso de Pós-graduação em Educação, Arte e História da Cultura e do curso de Pedagogia da Universidade Presbiteriana Mackenzie onde lidera dois grupos de pesquisa: GPAP Arte na Pedagogia e GPeMC - Mediação cultural: provocações e contaminações estéticas. Conselheira da América Latina junto à INSEA - International Society of Education through Art. Mestre em Artes pela ECA/USP e doutora em Educação pela Faculdade de Educação/USP.

ORCID: https://orcid.org/0000-0002-3418-0471

E-mail: mcmart@uol.com.br

Currículo: http://lattes.cnpq.br/7167254305943668

\section{Lucia Maria Salgado dos Santos Lombardi}

Professora do Curso de Pedagogia da Universidade Federal de São Carlos/Campus Sorocaba onde lidera o GIAPE - Grupo de pesquisa sobre Infância, Arte, Práticas Educativas e Psicossociais. Vice líder do GPAP - Grupo de Pesquisa Arte na Pedagogia. Membro do Fórum de Educação Infantil de Sorocaba e Região. Mestre e doutora em Educação pela Faculdade de Educação/USP.

ORCID: http://orcid.org/0000-0001-6978-864X

E-mail: lucialombar-diufscar@gmail.com

Currículo: http://lattes.cnpq.br/5697508831302188

Recebido em 30 de setembro de 2019 Aceito em 9 de dezembro de 2019 